\title{
Incidental gallbladder cancer and single-incision laparoscopic cholecystectomy
}

\author{
Karen E. Gibbs $\cdot$ Ronald N. Kaleya
}

Published online: 10 April 2009

(C) Springer Science+Business Media, LLC 2009

\section{Dear Editor,}

I enjoyed reading the article about incidental gallbladder cancers and the role of re-resection [1]. Recently, I was called by a pathologist and informed that a gallbladder specimen with a large polyp was consistent with a gallbladder cancer-a T1 lesion. The patient had undergone surgery with another surgeon and physical examination revealed a single incision.

When considering the possible technique used to retract and extract this gallbladder, I had reason for pause. Although this may not speak to all single-incision cholecystectomies, it is possible that the retraction process utilized for this procedure required the repeated passage of a needle through the body of the gallbladder, skin, and possibly the cancerous polyp. The gallbladder may have been opened or torn during the procedure. How was it extracted? With this in mind, even with a T1a gallbladder cancer, what do you do next?

As we embark on the world of "even more" minimally invasive surgery, we should not discard all of the surgical principles that we once held in esteem. There was a time when while performing an "old fashioned" laparoscopic cholecystectomy, if we entered the gallbladder/spilled bile, this was considered personally disappointing. Now, we purposely do this and it seems to be accomplished without regard-until the specimen comes back with gallbladder cancer. The previous article cited that gallbladder cancer is found in only $0.2-2.9 \%$ of cholecystectomies and that incidental findings are found in $0.5-1 \%$ of laparoscopies $[1,2]$.

This is an exciting time in minimally invasive surgery because the keen mind can be free to imagine and implement more slick and consumer-friendly approaches to the world of surgery. As we move forward, this is something for all of us to think about: but first, do no harm.

\section{References}

1. Goetze T, Paolucci V (2008) Immediate re-resection of $\mathrm{T} 1$ incidental gallbladder carcinomas: a survival analysis of the German Registry. Surg Endosc 22:2462-2465

2. Shimizu T, Arima Y, Yokomuro S, Yoshida H, Mamada Y, Nomura T, Taniai N, Aimoto T, Nakamura Y, Mizuguchi $\mathrm{Y}$, Kawahlgashi Y, Uchida E, Akimaru K, Tajiri T (2006) Incidental gallbladder cancer diagnosed during and after laparoscopic cholecystectomy. J Nippon Med Sch 73:136-140 